\title{
Energy and Economic Analysis of Curved, Straight, and Spiral Flow Flat-Plate Solar Water Collector
}

\author{
U. Muthuraman $\mathbb{D}^{1},{ }^{1}$ R. Shankar, ${ }^{2}$ Vinay Kumar Nassa, ${ }^{3}$ Alagar Karthick ${ }^{(D,}{ }^{4}$ \\ Chandrabhanu Malla $\mathbb{D}^{5},{ }^{5}$ Amit Kumar $\mathbb{D}^{6},{ }^{6}$ P. Manoj Kumar, Robbi Rahim ${ }^{7},{ }^{8}$ \\ and Murugesan Bharani ${ }^{9}{ }^{9}$
}

\footnotetext{
${ }^{1}$ Department of Electrical and Electronics Engineering, Francis Xavier Engineering College, Tirunelveli, 627003 Tamil Nadu, India ${ }^{2}$ Department of Electronics and Communication Engineering, Teegala Krishna Reddy Engineering College, Hyderabad 500097, India ${ }^{3}$ Department of Electronics and Communication Engineering, South Point Institute of Technology \& Management, Sonepat, 131001 Haryana, India

${ }^{4}$ Department of Electrical and Electronics Engineering, KPR Institute of Engineering and Technology, Avinashi Road, Arasur, Coimbatore, 641407 Tamil Nadu, India

${ }^{5}$ Department of Mechanical Engineering, Radhakrishna Institute of Technology and Engineering, Bhubaneswar, 752057 Odisha, India

${ }^{6}$ Department of Electronics, Bhaskaracharya College of Applied Sciences, University of Delhi, New Delhi 110075, India

${ }^{7}$ Department of Mechanical Engineering, KPR Institute of Engineering and Technology, Avinashi Road, Arasur, Coimbatore, 641407 Tamil Nadu, India

${ }^{8}$ Department of Informatics Management, Sekolah Tinggi Ilmu Manajemen Sukma, Medan, Sumatera Utara 20219, Indonesia

${ }^{9}$ School of Textile Leather and Fashion Technology, Kombolcha Institute of Technology, Wollo University, Kombolcha,

208 South Wollo, Ethiopia
}

Correspondence should be addressed to Murugesan Bharani; bharani.murugesan@kiot.edu.et

Received 17 February 2021; Revised 7 May 2021; Accepted 21 June 2021; Published 7 July 2021

Academic Editor: Regina De Fátima Peralta Muniz Moreira

Copyright (c) 2021 U. Muthuraman et al. This is an open access article distributed under the Creative Commons Attribution License, which permits unrestricted use, distribution, and reproduction in any medium, provided the original work is properly cited.

In this work, the solar water collector flow tube geometry is modified as curved and spiral to enhance the system's performance. The investigation is carried out experimentally under the meteorological conditions of the Kovilpatti region $\left(9^{\circ} 10^{\prime} 0^{\prime \prime} \mathrm{N}, 77^{\circ} 52^{\prime} 0^{\prime \prime} \mathrm{E}\right)$, Tamil Nadu, India. The flow pipes of the solar water heater are made of copper material which has higher thermal conductivity to recover the water heat as thermal energy. The influence of the mass flow rate (MF) on the flow pipes with respect to the surface temperature for various configurations of the flow tubes is investigated. The two MFs of $0.0045 \mathrm{~kg} / \mathrm{s}$ and $0.006 \mathrm{~kg} / \mathrm{s}$ are tested. The MF of $0.006 \mathrm{~kg} / \mathrm{s}$ yields the maximum efficiency of $73 \%$ compared to the other MF. The straight, curved, and spiral tubes yielded the maximum efficiency of $58 \%, 62 \%$, and $69 \%$, respectively, at $0.0045 \mathrm{~kg} / \mathrm{s}$. Similarly, the MF of $0.006 \mathrm{~kg} / \mathrm{s}$ obtained an efficiency of $62 \%, 65 \%$, and $73 \%$ for straight, curved, and spiral flow tubes, respectively. The economics and exergy of the system are analyzed. The maximum exergy efficiency of the collector is estimated to be $32 \%$ for the MF of $0.0045 \mathrm{~kg} / \mathrm{s}$ for the spiral flow collector, and for the $0.006 \mathrm{~kg} / \mathrm{s}$ MF, the obtained exergy efficiency is $27 \%$ for the spiral flow water heater. The economic analysis revealed that the expense is $\$ 0.0608$ and $\$ 0.0512$ worth of hot water produced for the domestic space heating.

\section{Introduction}

The loss of energy in the form of heat is inevitable in our everyday life. It plays a significant role and is used for various purposes, such as cooking, heating water, space heating, industrial process heating, and drying. Almost one-third of the world-generated energy is utilized in the form of heat. In addition, it is estimated that approximately $50 \%$ of the 


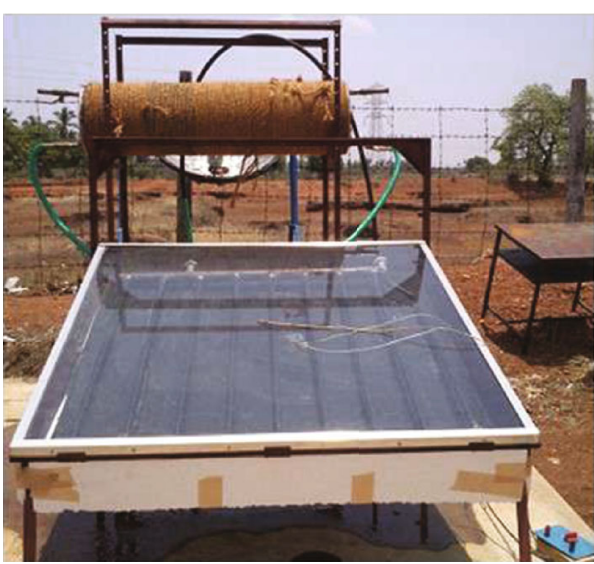

(a)

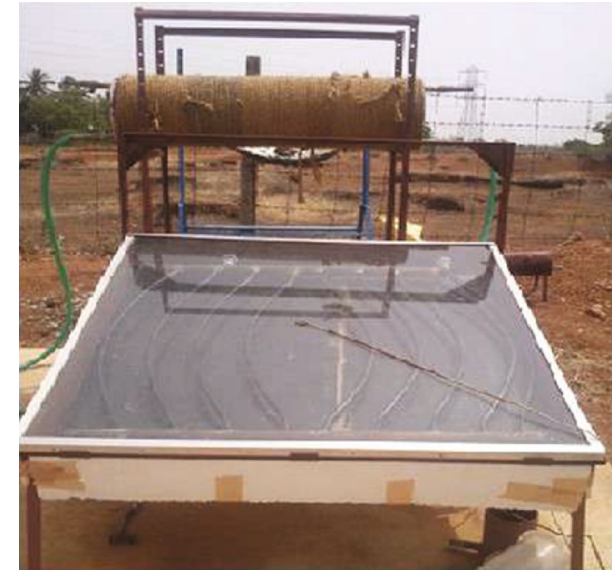

(b)

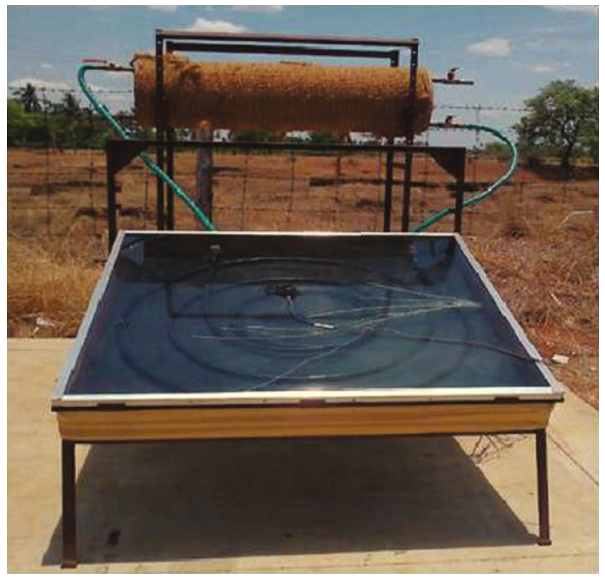

(c)

FigURE 1: Experimental setup of SWH with flow tubes of (a) straight tubes, (b) curved tubes, and (c) spiral tubes.

heat energy is expended on hot water requirements for different purposes $[1,2]$. It demonstrates the value of thermal energy and the need for hot water for humans. However, the requirements for hot water have been met in two main ways: electric heaters and fuel burning. Both of these means are correlated with higher energy costs and can cause severe environmental damage. In recent decades, the use of solar water heaters (SWHs) has become widespread among end users and provided their economy and viability in hot water generation [3]. They can be applied appropriately for a wide range of applications, from domestic water heating to industrial process heating with almost zero operating costs and energy independence $[4,5]$. The feasibility study on SWHs using the Monte Carlo method suggested constructing SWHs for the most economical generation of hot water. In most SWHs, the heat energy from the sun is recovered either with the aid of a flat-plate collector or with an evacuated tube collector to heat the water. In addition, a pump may be used if an active circulation of water is required; otherwise, a simple thermosyphon-dependent circulation is maintained without a pump $[6,7]$.

Despite the numerous advantages of SWHs, some obstacles, such as low thermal efficiency and low annual fractions, were caused by the intermittent solar radiation and compos- ite weather [8-10], integrating thermal storage materials [11], and modifying collector geometries [12]. The FPC and tube fin arrangement is introduced to improve its performance [13]. They concluded that the rod-type enhancers showed a more significant improvement than the tube-type enhancer and that the performance enhancement factor was increased to $1.38 \%$. In another study, the surface of the FPC was studied following the introduction of convective barriers. The results showed that the heat loss was substantially reduced by increasing the number of barriers, which improved the system's efficiency [14]. The screen mesh [15] was investigated to improve the performance of the solar collector heat pipe. Methanol was used as working fluid in the water heater. They found that the efficiency improved with the mesh number, and the optimum mesh number was suggested as 100 mesh per inch of the condenser segment. The benefit of using different types of phase change materials (PCMs) had also been studied in several studies to improve the performance of solar collectors [16-18]. The experiment is with a SWH coupled with an oscillating heat pipe and a PCM [19]. They confirmed that the PCM had reduced the output fluctuations by $30 \%$ and increased the outlet water temperature to $50^{\circ} \mathrm{C}$. The impact of paraffin-based PCM [20] was investigated on the annual solar portion of the 


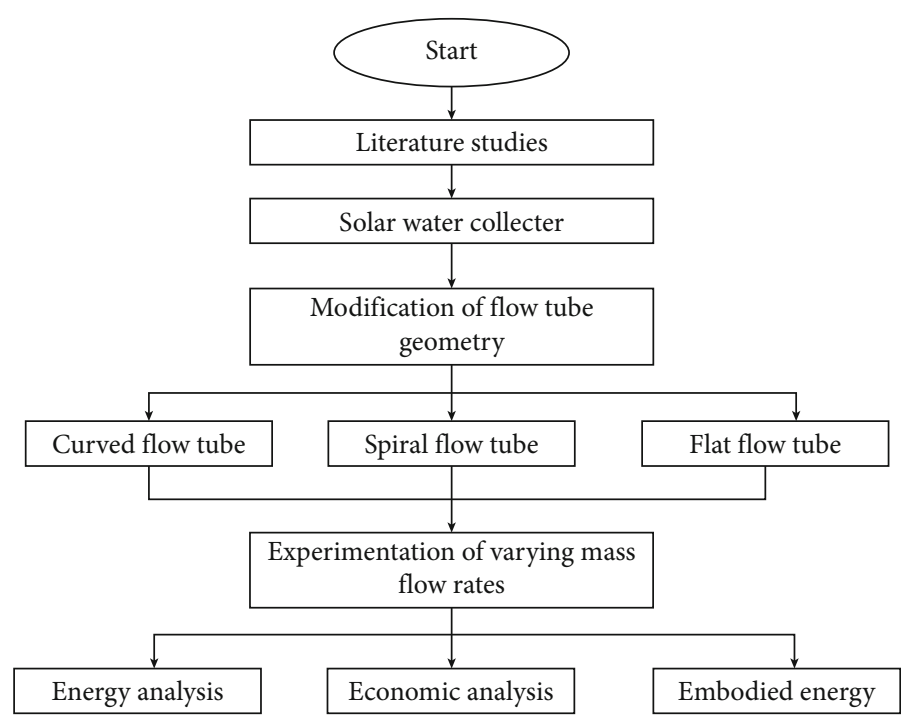

Figure 2: Flowchart of the study.

TABLE 1: Instrument specifications.

\begin{tabular}{|c|c|c|c|}
\hline Instrument & Range & Accuracy & Uncertainty (\%) \\
\hline Solar radiation meter (PYRA $300 \mathrm{~V} 2$ ) & $0-1800 \mathrm{~W} / \mathrm{m}^{2}$ & \pm 1 & 0.57 \\
\hline Temperature indicator (RTD Pt $100 \Omega$ class A) & $0-100^{\circ} \mathrm{C}$ & $\pm 0.3^{\circ} \mathrm{C}$ & 0.017 \\
\hline Thermocouple wire (K-type) & $0-220^{\circ} \mathrm{C}$ & $\pm 0.1^{\circ} \mathrm{C}$ & 0.057 \\
\hline Measuring jar & $0-1000 \mathrm{~mL}$ & $\pm 1 \mathrm{~mL}$ & 0.57 \\
\hline
\end{tabular}

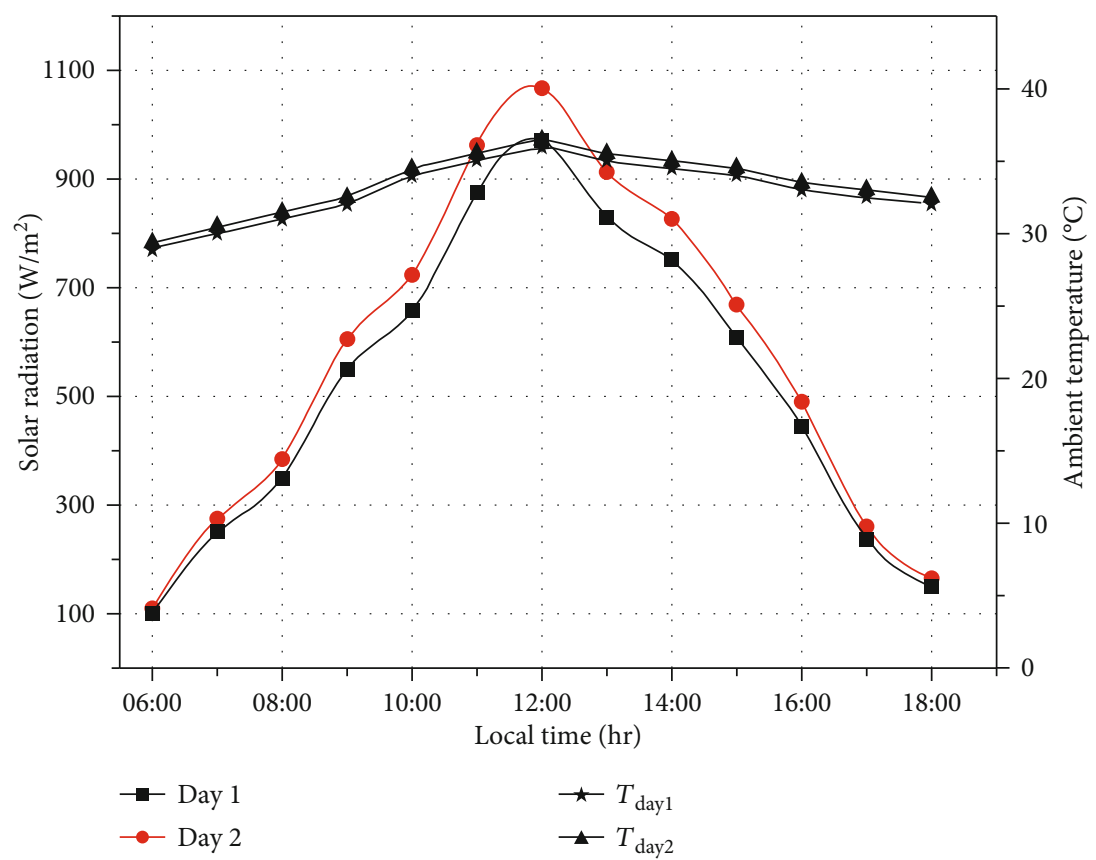

FIgURE 3: Hourly variation of (a) solar radiation and (b) ambient temperature of Kovilpatti 2020 during summer.

evacuated solar tube collector. A reported 20.5\% improvement in the efficiency of their SWH is recorded with PCM support. Several other works of literature have discussed the possibilities of using nanoadditive-based fluids to increase the performance of solar collectors [21, 22]. Michael and Iniyan [23] tested a nanofluid containing copper oxide nanoparticles in water as a working fluid in a flat-plate SWH under different flow conditions. The experiment showed that 


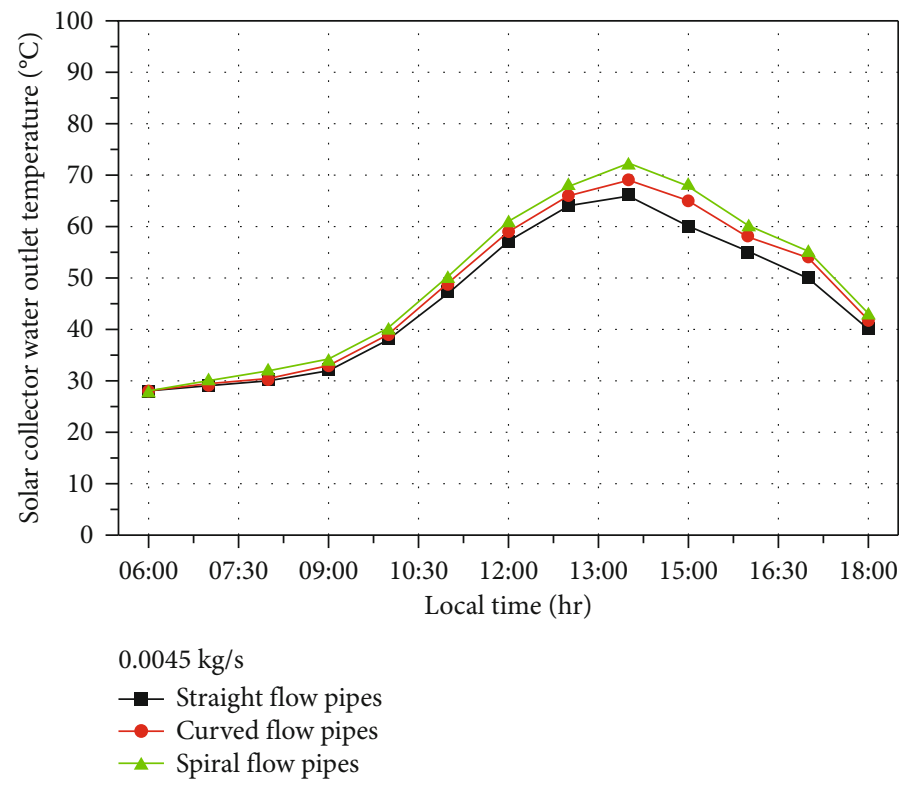

(a)

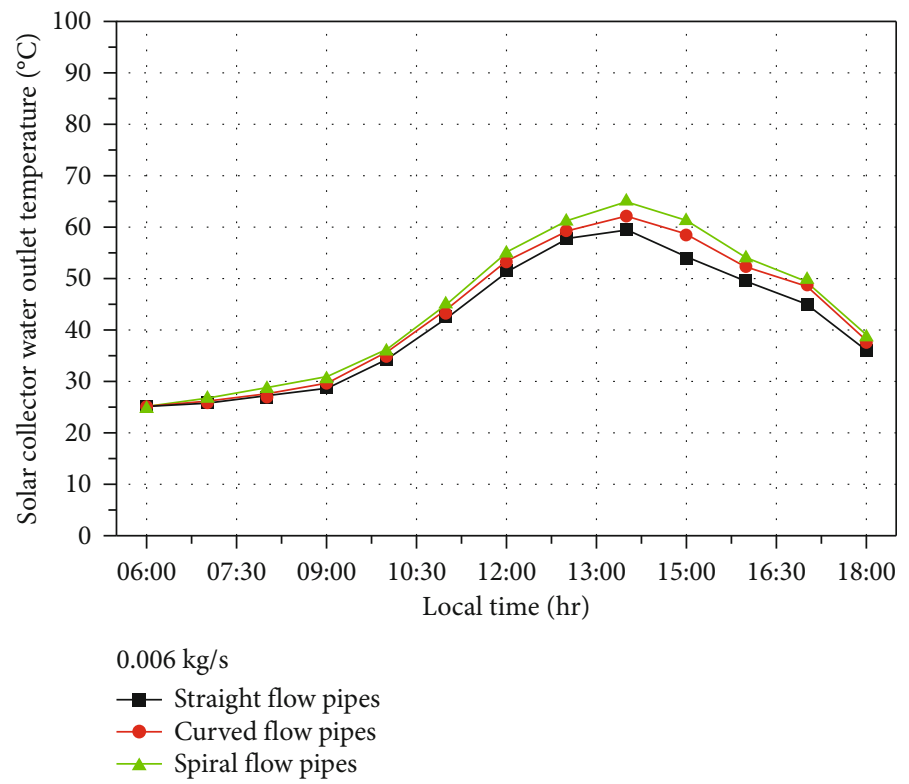

(b)

Figure 4: Hourly variation of the outlet water temperature at the MF of (a) $0.0045 \mathrm{~kg} / \mathrm{s}$ and (b) $0.006 \mathrm{~kg} / \mathrm{s}$.

the nanofluid increased the collector's thermal efficiency by $6.3 \%$. The comprehensive review on the heating and cooling process using nanomaterials for lubricant is reviewed in Refs. [24, 25].

Flat-plate SWHs had been deployed worldwide in several numbers due to their simple design and lower costs relative to other types of SWHs. However, the necessary design and geometry were the critical factors in determining the efficient performance of the FPC system, especially for systems operating under thermosyphon flow conditions. The effect of connecting a mantle-shaped heat exchanger to a flat-plate solar collector was reported (see Ref. [26]). The mantleshaped heat exchanger had been documented to reduce the system's efficiency regularly.
The FPC was numerically evaluated with the effect of the dimples on the tubes of FPCs to improve the heat transfer [27]. It was concluded that the heat transfer has been increased by $32.3 \%$. On the other hand, the dimples increased the friction factor of the tubes by around $11 \%$, which were not a helpful phenomenon in this type of the system. In a recent study [28], helical-shaped corrugated risers had been tested as a heat transfer enhancement mechanism for a FPC and have enriched the thermal output factor by 2.3. Silva and Salviano [29] examined a FPC fitted with a distinctively built winglet-type vortex SWH. The results showed an improvement in heat transfer but significantly increased friction resistance of the flow. Deployment of helical inserts within the flow tubes improves the flat-plate SWH [30]. 


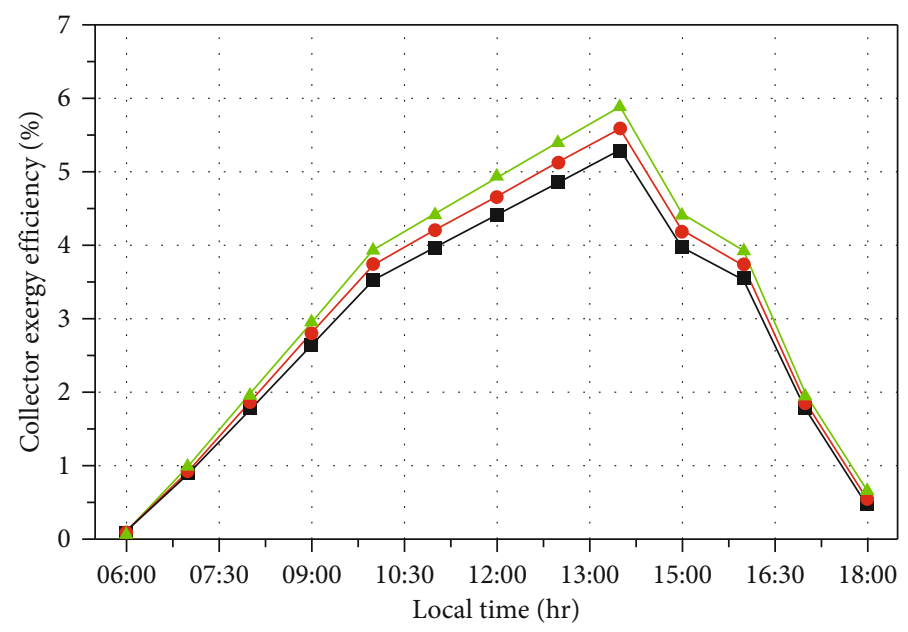

$0.0045 \mathrm{~kg} / \mathrm{s}$

- Straight flow pipes

- Curved flow pipes

- Spiral flow pipes

(a)

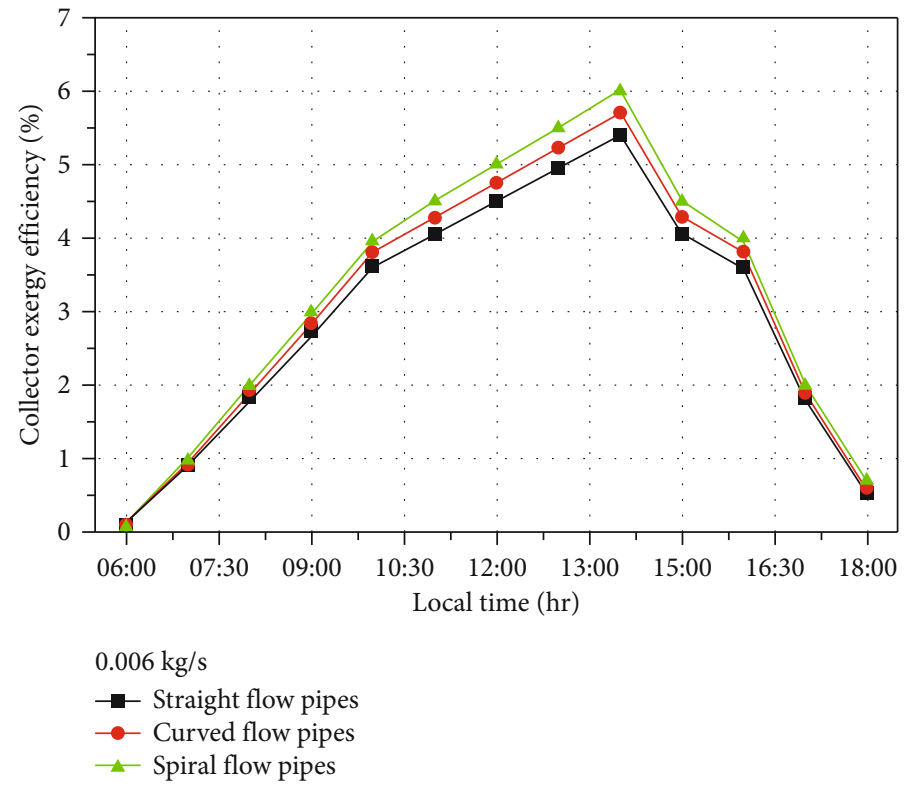

(b)

Figure 5: Hourly variation of the solar water collector thermal efficiency at the MF of (a) $0.0045 \mathrm{~kg} / \mathrm{s}$ and (b) $0.006 \mathrm{~kg} / \mathrm{s}$.

Extensive literature studies had shown a great deal of potential to increase the performance of flat-plate SWHs without incurring additional costs and material by modifying the collector geometry. In addition, the previous literature has shown that flow parameters are significant factors and must be critically studied in the implementation of any improvements to the solar collector geometry to achieve maximum performance from the SWH. In this work, the efficiency of the flat-plate SWH is studied and compared with three different geometric configurations of the flow tubes: one with a straight layout, the second with a curved layout, and the third with a spiral layout. Significant improvements are seen in the efficiency of the SWH and are stated in the following section.
The economic and embodied energy analysis of the system is carried out for the feasibility study.

\section{Materials and Method}

2.1. Materials. The investigated SWH is shown in Figure 1, which includes a solar collector with various flow tubes, such as a straight, curved, and spiral-shaped flowing water system, and measuring instruments. The SWH system is composed of a storage system, flow tubes, and a primary control valve that regulated the MF of the water. The absorber plate is coated with the black color to absorb a larger amount of heat energy. The glass cover is used to insulate the surface and 
TABLE 2: Comparison of the SWH with different geometry flow tubes.

\begin{tabular}{lcc}
\hline Flow tube geometry & Research finding & Reference \\
\hline Twist tape & 9.29 higher than conventional SWH & {$[37]$} \\
Helically twisted tape & Collector efficiency improved by $3.9 \%$ & {$[38]$} \\
Dimple tube & The average temperature is $69^{\circ} \mathrm{C}$ & {$[39]$} \\
Left-right twisted tape & Instantaneous efficiency is found $(85 \%)$ & {$[40]$} \\
A zigzag pattern & $62.90 \%$ efficiency was obtained & Present study \\
Circular flow pipes & $65 \%$ efficiency was obtained & Present study \\
Spiral flow pipes & $73 \%$ efficiency was obtained & \\
\hline
\end{tabular}

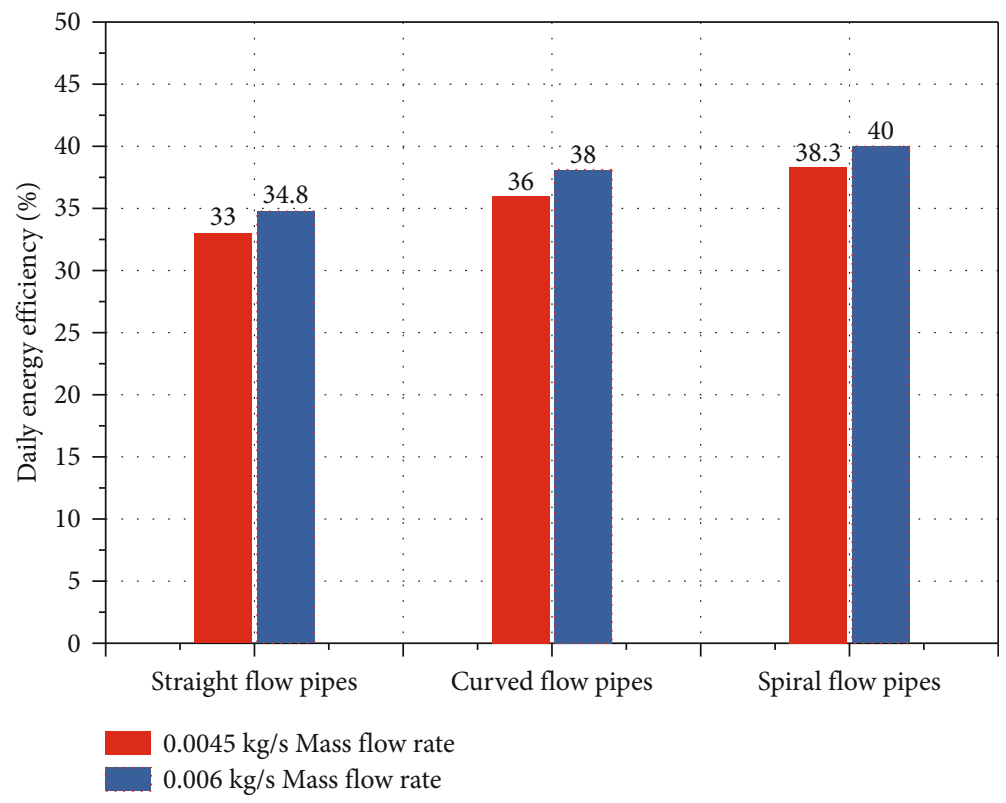

Figure 6: Mean daily thermal efficiency of the solar collector.

allow the light energy to strike on the surface of the collector with $4 \mathrm{~mm}$ thickness. SWH walls are insulated with thermocol to reduce conduction losses. The SWH is shifted to the sun's location and held at an inclination angle of $9^{\circ}$ of the site. The various surface temperature of the SWH is measured and plotted. The inlet and outlet water temperature is measured using a thermocouple wire. According to the position of the collector, a frame of wood of appropriate dimensions supports the solar water collector. A SWH entrance and outlet tube is installed so that the copper tube can be similarly locked in the insulated box so that the thermal energy of the solar insolation can be used best. Figure 2 shows the flowchart of the study.

The experiment took place in March 2020 at Kovilpatti, National Engineering College, in Tamil Nadu, India. The experiments are conducted on different mass flows of 0.0045 and $0.006 \mathrm{~kg} / \mathrm{s}$ which were chosen to perform the experimentations. Water flowed through the straight, curved, and spiral flow tubes of the SWH system from the top of the absorber plate. As solar radiation continuously fell on top of the glass cover, this resulted in water heating. Moreover, the water traveled across the floor of the solar heating systems, which is shown in Figure 2, and the used instrument is listed in Table 1 .

2.2. Methods. The main objective of this study is to enhance the performance of the SWH by modifying the flow tubes of the solar collector. The experimentation was carried out during March 2020. Energy and exergy analysis of the SWH was analyzed with various flow tubes such as straight, curved, and spiral flow. The systematic study was formulated, and the performance of the SWH was analyzed. Three SWHs were designed and fabricated with the dimension of $1 \mathrm{~m} \times 1 \mathrm{~m}$. Each SWH was incorporated with specially designed flow tubes such as straight, curved, and spiral flow tubes. The incident solar radiation on the solar collector and ambient parameters were measured using mini meteorological stations throughout the day.

(1) FPCs should be fixed at a particular angle according to the locality so that maximum solar radiation can be absorbed efficiently

(2) Initially, a straight-type copper tube is installed inside a FPC to analyze the performance, followed by a spiral tube and a curved tube 


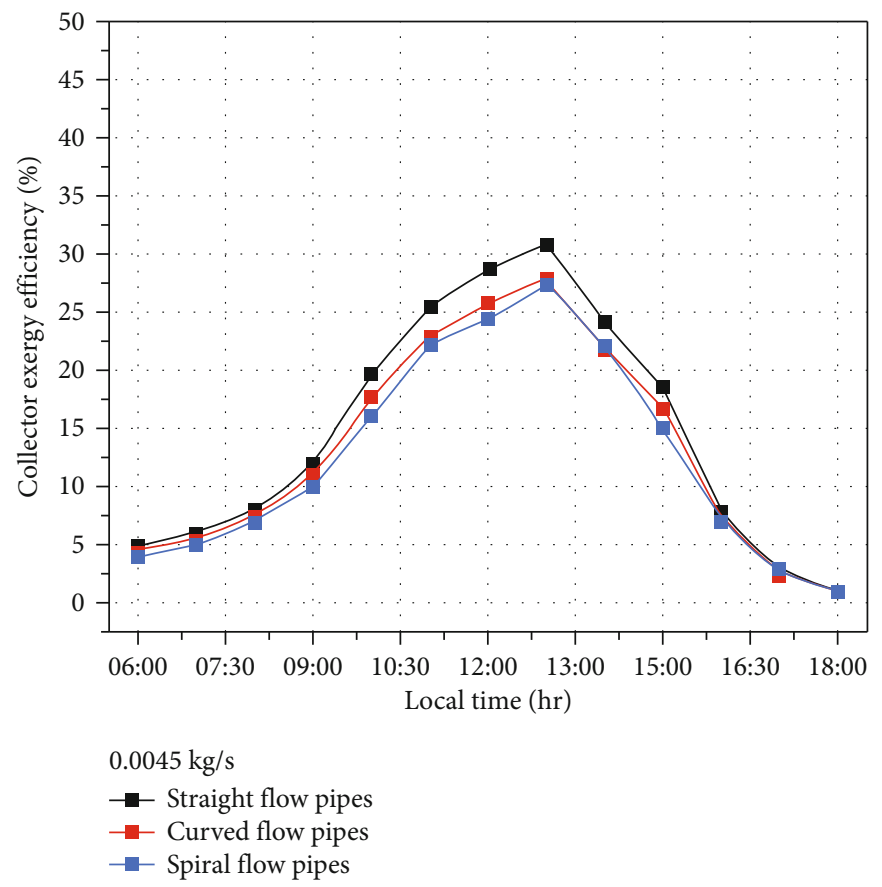

(a)

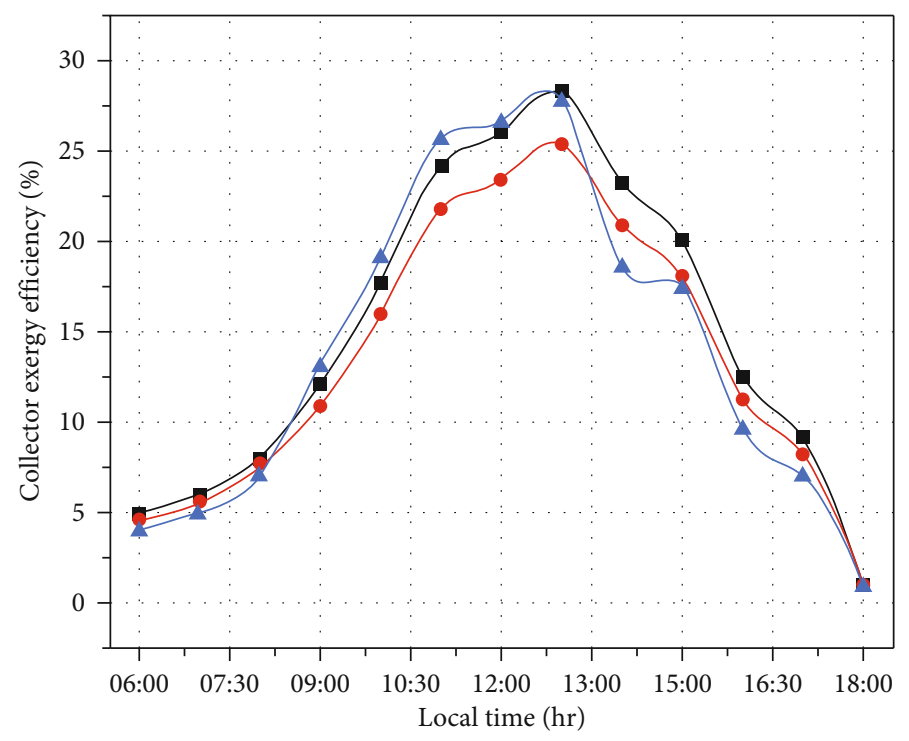

$0.006 \mathrm{~kg} / \mathrm{s}$

$\rightarrow$ - Straight flow pipes

$\rightarrow$ Curved flow pipes

$\leftarrow$ Spiral flow pipes

(b)

FIGURE 7: Hourly variation of the exergy efficiency of the solar collector at the MF of (a) $0.0045 \mathrm{~kg} / \mathrm{s}$ and (b) $0.006 \mathrm{~kg} / \mathrm{s}$.

(3) Two header pipes were provided for the circulation of water in and out of the collector. Curved-type and straight-type copper tubes should be attached between the two header pipes with equal distance spacing

(4) A storage tank was placed above the solar collector for storing the water. As the water gets heated up while flowing through the tubes, there occurs a temperature difference

(5) This temperature difference also causes density variation that causes the natural circulation of water based on the thermosyphon effect. In terms of time, a simple beaker is used to measure the MF of the water on a volume basis 


\section{Experimental Uncertainty}

Error is the difference between the value measured and the actual value of the value measured. Two forms of error exist: sporadic and structural. Random errors are changed as tests are performed under stable conditions, but structural errors cannot be changed. The integrated method quantifies uncertainty concerning experimental effects [31]. The type B errors are measured as the precision and calibration characteristics. In this analysis, all individual measurement parameters are uniformly distributed. The experiments mentioned here have independent parameters: absorber surface temperature and water outlet temperature. Uncertainty for form B is the regular expression of $[31,32]$

$$
\text { un }=\frac{\text { ay }}{\sqrt{3}}
$$

where "un" is the standard uncertainty and "ay" is the device's precision identified by the device manufacturer. Table 1 shows the difficulties concerning the experimental equipment. The uncertainty of efficiency is calculated as $0.052 \%$.

\section{Results and Discussion}

4.1. Energy Analysis of the Solar Water Heating System. Solar radiation mainly depends on local weather and location. In March 2020, the experimentations were carried out with clear sky conditions. The output of a flat-plate SWH with various flow pipes is evaluated. The sample experimental days are presented for the MF of 0.0045 and $0.006 \mathrm{~kg} / \mathrm{s}$ during March 12, 2020, and March 15, 2020, respectively. The experimentation day is represented as day 1 and day 2. The energy collected is converted to the thermal energy of water in the pipes. Thus, the inlet temperature $T_{\mathrm{i}}$ is not the same as the outlet temperature $T_{\mathrm{o}}$. The amount of energy gained is calculated using the following equation:

$$
Q=m C_{\mathrm{p}} *\left(T_{\mathrm{o}}-T_{\mathrm{i}}\right)
$$

where $m$ is the MF water and $C_{p}$ is the specific heat of the water.

The collector efficiency is obtained by using the relation

$$
\eta=\frac{Q}{A_{\mathrm{c}} * I},
$$

where $A_{\mathrm{c}}$ is the collector area $\left(\mathrm{m}^{2}\right)$ and $I$ is the solar intensity.

Figure 3 shows the hourly variation of solar radiation and ambient temperature of day 1 and day 2 of the Kovilpatti region. Figure 4 shows the hourly differences in temperature between incoming and outlet water, the solar collector capacity, and the comparison of straight, curved, and spring solar flow tubes for SWH's experimental day ambient parameter. It is inferred from Figure 4 that suggests daytime temperature variation for various MFs for the SWH's straight, curved, and spiral flow tubes. It indicates that the solar collector's temperature increases as predicted by the rise in solar radiation and
TABLE 3: Investment cost of SWH.

\begin{tabular}{lccc}
\hline \multirow{2}{*}{ Components } & \multicolumn{3}{c}{ The total cost of the system (\$) } \\
& FPC & CFC & SFC \\
\hline Flow pipes (copper tubes) & 40.9 & 42.2 & 39.0 \\
Collector area & 51.9 & 51.9 & 51.9 \\
Acrylic sheets & 7.8 & 7.8 & 7.8 \\
Structure stand & 9.7 & 9.7 & 9.7 \\
Absorber black coating & 1.6 & 1.6 & 1.6 \\
Fabrication labor cost & 13.0 & 13.0 & 13.0 \\
Total cost & 125.0 & 126.3 & 123.1 \\
\hline
\end{tabular}

peaks at 14.00. The whole day at that time is the solar strength. Temperature variation increases with lower $\mathrm{MF}$. The temperature is a maximum of $66^{\circ} \mathrm{C}, 69^{\circ} \mathrm{C}$, and $72^{\circ} \mathrm{C}$ for straight, curved, and spiral flow tubes with a $\mathrm{MF}$ of $0.0045 \mathrm{~kg} / \mathrm{s}$ and a minimum of $29^{\circ} \mathrm{C}$ with a $\mathrm{MF}$ of $0.0045 \mathrm{~kg} / \mathrm{s}$. As the MF increases from 0.0045 to $0.006 \mathrm{~kg} / \mathrm{s}$, the outlet water temperature decreases.

The effect of intermittent solar radiation may affect the surface temperature of the collector which indirectly reduces the system efficiency. The mean temperature difference of the solar water channel is seen in the output temperature of the solar water channel during two test days at the corresponding MF. A significant factor in assessing system performance is the temperature differential. Figure 5 shows that the system temperature difference is decreased with a rising MF. For SWHs with straight, curved, and spiral tubes, the temperature variations of the mass flow of $0.0045 \mathrm{~kg} / \mathrm{s}$ are, respectively, $38^{\circ} \mathrm{C}, 41^{\circ} \mathrm{C}$, and $44^{\circ} \mathrm{C}$.

Figure 5 shows the integrated relationship between the $\mathrm{MF}$ and the hourly variation on the energy conversion efficiency of the SWH with different flow tubes, including straight, curved, and spiral flow tubes, in two experimental days. On the first day, the MF for the water is $0.0045 \mathrm{~kg} / \mathrm{s}$, which is the highest day with a straight, curved, and spiral efficiency of $58 \%, 62 \%$, and $69 \%$, respectively. The water MF is increased to detect a change in the device efficiency after the first experimental day. The thermal efficiency of the system has been considerably improved. On the second day, efficiency is $62 \%, 65 \%$, and $73 \%$ at a MF of $0.006 \mathrm{~kg} / \mathrm{s}$ for straight, curved, and spiral tubes, respectively. The increased MF contributes to an increase in the heat transfer coefficient, and consequently, the efficiency is increased [5, 13]. The performance of the SWH depends on incident solar radiation, $\mathrm{MF}$, and configuration of the flow tube geometry [33]. The variation in the geometry of the SWH induces the flow of the liquid medium that also enhances the performance of the spiral flow collector. The performance of the solar water collector is compared with the different geometries of the flow tube, and it is presented in Table 2.

Figure 6 indicates a variation of the mean day-to-day solar flow-tube thermal efficiency collector of two different mass flow speeds. The energy derived from solar radiation is $43 \mathrm{MJ}$ at a $\mathrm{MF}$ of $0.006 \mathrm{~kg} / \mathrm{s}$. The energy provided by the solar water collector is $14.7 \mathrm{MJ}$. The remaining water in the tank had supplied energy at 10.1 MJ. Therefore, the average 
TABLE 4: Cost analysis of the proposed SWH.

\begin{tabular}{lcccccc}
\hline SWH (kg/s) & $\begin{array}{c}\text { Electrical energy savings } \\
(\mathrm{kWh} / \text { day) }\end{array}$ & Fabrication cost (Rs) & Annual cost/kg & $\begin{array}{c}\text { Useful energy } \\
\text { (kWh/annum) }\end{array}$ & Cost (kWh/annum) & EPBT (years) \\
\hline FPC (0.004) & 2 & 125 & 0.0064 & 474.5 & 0.0608 \\
FPC (0.006) & 2.25 & 125 & 0.0072 & 533.8 & 0.0540 \\
CFC (0.004) & 2.4 & 126.3 & 0.0076 & 569.4 & 0.0512 \\
CFC (0.006) & 2.6 & 126.3 & 0.0082 & 616.8 & 0.0473 \\
SFC (0.004) & 2.7 & 123 & 0.0088 & 640.5 & 0.0443 \\
SFC (0.006) & 2.9 & 123 & 0.0094 & 688.0 & 0.0413 & 1.96 \\
\hline
\end{tabular}

TABLE 5: Embodied energy for the SWH.

\begin{tabular}{lc}
\hline Components & Embodied energy $(\mathrm{kWh})$ \\
\hline Storage tank FRP & 450 \\
Acrylic & 475 \\
Structure stand & 180 \\
Absorber paint & 6.66 \\
Thermocol & 55 \\
Fittings & 45 \\
Total & 1211 \\
\hline
\end{tabular}

calculated daily thermal efficiency is $40 \%$ for the MF of $0.006 \mathrm{~kg} / \mathrm{s}$. The energy derived from solar radiation at a MF of $0.006 \mathrm{~kg} / \mathrm{s}$ is $46 \mathrm{MJ}$.

The energy transferred from the drained water system contributed to $19 \mathrm{MJ}$. The energy provided by the rest of the water was $5.6 \mathrm{MJ}$. The estimated mean thermal efficiency is $33 \%$ for the MF of $0.0045 \mathrm{~kg} / \mathrm{s}$, for straight flow tubes of the $\mathrm{SWH}$. The curved and spiral flow tubes of solar water collectors have $36 \%$ and $38.3 \%$ efficiencies, respectively, at 0.0045 $\mathrm{kg} / \mathrm{s}$ flow, as shown in Figure 6.

4.2. Exergy Analysis of the Solar Water Heating System. It is possible to evaluate the second law efficiency of the system (destruction of energy) that was for the possible input to the system how much work can be extracted from the system. The exergy of the SWH with a comparison of the straight, curved, and spiral flow SWHs is analyzed. The exergy efficiency of the system is given as

$$
\begin{gathered}
\eta_{\text {exe }}=\frac{\mathrm{Ex}_{\text {out }}}{\mathrm{Ex}_{\text {in }}}, \\
\operatorname{Ex}_{\text {out }} \frac{m_{o} L_{h}}{3600} X\left[1-\frac{T_{\mathrm{a}}}{T_{\mathrm{w}}}\right] .
\end{gathered}
$$

The exergy input of the system is expressed as follows:

$$
\mathrm{Ex}_{\mathrm{in}}=A_{\mathrm{e}} I(t) X\left[1-\frac{4}{3}\left(\frac{T_{\mathrm{a}}}{T_{\mathrm{s}}}\right)+\frac{1}{3}\left(\frac{T_{\mathrm{a}}}{T_{\mathrm{s}}}\right)^{4}\right],
$$

where $A_{\mathrm{e}}$ is the area of the collector $\left(\mathrm{m}^{2}\right)$ and $I(t)$ is the solar radiation $\left(\mathrm{W} / \mathrm{m}^{2}\right)$. A container should be put on an incline temperature of $6000 \mathrm{~K}$. The exergy analysis of the SWH is calculated for various geometries such as straight, curved, and spiral collectors. The maximum exergy efficiency of the collector is estimated as $32 \%$ for the MF of $0.004 \mathrm{~kg} / \mathrm{s}$ at the spiral flow collector, while for the $0.006 \mathrm{~kg} / \mathrm{s} \mathrm{MF}$, the obtained exergy efficiency is $27 \%$ for a spiral flow water heater, which is plotted in Figures 7(a) and 7(b).

4.3. Solar Water Heater Economic Evaluation. The significant feature of the SWH for the residential building is the annual energy savings due to the thermal energy gain. The annual energy gain is considered based on the energy provided by the SWH and the reduction of the heating load during its lifetime [34]. The capital cost of the SWH is listed in Table 3.

$$
\mathrm{CRF}=\frac{r(1+r)^{n}}{(1+r)^{n}-1} .
$$

CRF is the capital recovery factor of the device. The interest rate $(r)$ and the scheme's period which are supposed to last $n$ are $12 \%$ and 10 years, respectively.

$$
\text { Sinking factor fund }=\frac{r}{(1+r)^{n}-1} .
$$

Here, the system's salvage value $(S)$ is taken as $20 \%$ of the system's capital cost $(P)$. An equation calculates the sinking fund factor using equation (8).

The costs of SWHs produced by these systems are shown in Table 4. The SWH with modified flow tubes may affect the expense of $\$ 0.0608$ and $\$ 0.0512$ worth of hot water produced for the domestic space heating.

4.4. Embodied Energy. The embodied energy consists of valuing the energy used to transport the raw material, producing the components, installing and maintaining the component, and installing the product in the house [35]. The breakdown of energy used for the system components has been listed in Table 5. The embodied energy is $1211 \mathrm{kWh}$.

4.5. Energy Payback Time (EPBT). The EPBT is a ratio of the energy used by the SWH system, which is the average annual energy savings by thermal gains [36]. It is given as follows:

$$
\operatorname{EPBT}(\text { years })=\frac{E_{\text {in }} \mathrm{kWh}}{E_{\text {out }}(\mathrm{kWh} / \text { year })} .
$$

The average EPBT payback period of the SWH is 2 years. The proposed SWH EPBT is listed in Table 4. 


\section{Conclusion}

The comparative performance of the modified SWH is experimentally examined for various flow tubes, including straight, curved, and spiral tubes. The MF is inversely proportional to the difference in temperature between the input and outlet flows.

(i) The maximum difference in temperature is reported at a MF of $0.0045 \mathrm{~kg} / \mathrm{s}$. However, the temperature differential is directly related to solar radiation and increases as solar radiation raises the surface temperature

(ii) The two MFs are tested, such as 0.0045 and 0.006 $\mathrm{kg} / \mathrm{s}$. The MF of $0.006 \mathrm{~kg} / \mathrm{s}$ yields the maximum efficiency of $73 \%$ compared to the other MF

(iii) The straight, curved, and spiral tubes yielded the maximum efficiency of $58 \%, 62 \%$, and $69 \%$, respectively, at $0.0045 \mathrm{~kg} / \mathrm{s}$. Similarly, the MF of 0.0045 $\mathrm{kg} / \mathrm{s}$ obtained an efficiency of $62 \%, 65 \%$, and $73 \%$ for straight, curved, and spiral flow tubes, respectively

This work will help the stakeholder and architects to design the domestic heating with the SWH. A SWH without modification of the flow tubes would have a $5 \%$ increase in resources. The economic analysis revealed that the expense is $\$ 0.0608$ and $\$ 0.0512$ worth of hot water produced for the domestic space heating.

\section{Nomenclature}

MF: Mass flow rate

SWH: Solar water heater

FPC: Flat-plate solar collector

CFC: Curved flow solar collector

SFC: Spiral flow solar collector

EPBT: Energy payback time

$m_{\mathrm{o}}: \quad$ Amount of freshwater $(\mathrm{kg} / \mathrm{h})$

$L_{\mathrm{h}}$ : $\quad$ Latent heat of vaporization $(\mathrm{J} / \mathrm{kg} \mathrm{K})$

$T_{\mathrm{a}}$ : $\quad$ Ambient temperature

$T_{\mathrm{w}}: \quad$ Water temperature.

\section{Data Availability}

The data used to support the findings of this study are included within the article.

\section{Conflicts of Interest}

The authors declare that there is no conflict of interest regarding the publication of this article.

\section{References}

[1] R. Kabilan, V. Chandran, J. Yogapriya et al., "Short-term power prediction of building integrated photovoltaic (BIPV) system based on machine learning algorithms," International Journal of Photoenergy, vol. 2021, 11 pages, 2021.

[2] R. Naveenkumar, M. Ravichandran, B. Stalin et al., "Comprehensive review on various parameters that influence the performance of parabolic trough collector," Environmental Science and Pollution Research, vol. 28, no. 18, pp. 2231022333, 2021.

[3] H. Benli, "Potential application of solar water heaters for hot water production in Turkey," Renewable and Sustainable Energy Reviews, vol. 54, pp. 99-109, 2016.

[4] A. Rout, S. S. Sahoo, and S. Thomas, "Risk modeling of domestic solar water heater using Monte Carlo simulation for eastcoastal region of India," Energy, vol. 145, pp. 548-556, 2018.

[5] P. Reddy, M. V. N. Surendra Gupta, S. Nundy, A. Karthick, and A. Ghosh, "Status of BIPV and BAPV system for less energy-hungry building in India-a review," Applied Sciences, vol. 10, no. 7, p. 2337, 2020.

[6] A. Mostafaeipour, M. Zarezade, H. Goudarzi, M. RezaeiShouroki, and M. Qolipour, "Investigating the factors on using the solar water heaters for dry arid regions: a case study," Renewable and Sustainable Energy Reviews, vol. 78, pp. 157166, 2017.

[7] A. Karthick, K. Kalidasa Murugavel, A. Ghosh, K. Sudhakar, and P. Ramanan, "Investigation of a binary eutectic mixture of phase change material for building integrated photovoltaic (BIPV) system," Solar Energy Materials and Solar Cells, vol. 207, 2020.

[8] P. Manoj Kumar, K. Mylsamy, and P. T. Saravanakumar, "Experimental investigations on thermal properties of nano$\mathrm{SiO}_{2} /$ paraffin phase change material (PCM) for solar thermal energy storage applications," Energy Sources, Part A: Recovery, Utilization, and Environmental Effects, vol. 42, no. 19, pp. 2420-2433, 2020.

[9] M. E. H. Attia, A. Karthick, A. M. Manokar et al., "Sustainable potable water production from conventional solar still during the winter season at Algerian dry areas: energy and exergy analysis," Journal of Thermal Analysis and Calorimetry, 2020.

[10] M. Dinesh Babu and M. Venkata Ramanan, "Experimental analysis of the performance of a solar flat plate water heater with and without internal fins," International Journal of Ambient Energy, vol. 38, no. 6, pp. 582-589, 2017.

[11] A. Karthick, K. K. Murugavel, and P. Ramanan, "Performance enhancement of a building-integrated photovoltaic module using phase change material," Energy, vol. 142, pp. 803-812, 2018.

[12] M. Moravej, M. R. Saffarian, L. K. B. Li, M. H. Doranehgard, and Q. Xiong, "Experimental investigation of circular flatpanel collector performance with spiral pipes," Journal of Thermal Analysis and Calorimetry, vol. 140, no. 3, pp. 12291236, 2020.

[13] K. Balaji, P. Ganesh Kumar, D. Sakthivadivel, V. S. Vigneswaran, and S. Iniyan, "Experimental investigation on flat plate solar collector using frictionally engaged thermal performance enhancer in the absorber tube," Renewable Energy, vol. 142, pp. 62-72, 2019.

[14] P. Manoj Kumar, K. Mylsamy, K. Alagar, and K. Sudhakar, "Investigations on an evacuated tube solar water heater using hybrid-nano based organic phase change material," International Journal of Green Energy, vol. 17, no. 13, 2020.

[15] T. Brahim, M. H. Dhaou, and A. Jemni, "Theoretical and experimental investigation of plate screen mesh heat pipe solar collector," Energy Conversion and Management, vol. 87, pp. 428-438, 2014.

[16] M. Eltaweel, A. A. Abdel-Rehim, and H. Hussien, "Indirect thermosiphon flat-plate solar collector performance based on 
twisted tube design heat exchanger filled with nanofluid," International Journal of Energy Research, vol. 44, no. 6, pp. 4269-4278, 2020.

[17] A. Karthick, M. M. Athikesavan, M. K. Pasupathi, N. M. Kumar, S. S. Chopra, and A. Ghosh, "Investigation of inorganic phase change material for a semi-transparent photovoltaic (STPV) module," Energies, vol. 13, no. 14, 2020.

[18] H. Yongtai, X. Lixian, and Y. Yaohua, "Study on design and thermal characteristics of vacuum tube solar collector intubated with heat storage tube," International Journal of Energy Research, vol. 43, no. 13, pp. 7409-7420, 2019.

[19] W. Wu, S. Dai, Z. Liu et al., "Experimental study on the performance of a novel solar water heating system with and without PCM," Solar Energy, vol. 171, pp. 604-612, 2018.

[20] P. Feliński and R. Sekret, "Effect of PCM application inside an evacuated tube collector on the thermal performance of a domestic hot water system," Energy and Buildings, vol. 152, pp. 558-567, 2017.

[21] V. Krishnavel, A. Karthick, and K. K. Murugavel, "Experimental analysis of concrete absorber solar water heating systems," Energy and Buildings, vol. 84, pp. 501-505, 2014.

[22] C. S. Dhanalakshmi, P. Madhu, A. Karthick, M. Mathew, and R. Vignesh Kumar, "A comprehensive MCDM-based approach using TOPSIS and EDAS as an auxiliary tool for pyrolysis material selection and its application," Biomass Conversion and Biorefinery, 2020.

[23] J. J. Michael and S. Iniyan, "Performance of copper oxide/water nanofluid in a flat plate solar water heater under natural and forced circulations," Energy Conversion and Management, vol. 95, pp. 160-169, 2015.

[24] L. Yang, W. Jiang, W. Ji et al., "A review of heating/cooling processes using nanomaterials suspended in refrigerants and lubricants," International Journal of Heat and Mass Transfer, vol. 153, p. 119611, 2020.

[25] L. Yang, J. N. Huang, and F. Zhou, “Thermophysical properties and applications of nano-enhanced PCMs: an update review," Energy Conversion and Management, vol. 214, article 112876, 2020.

[26] J. Huang, S. Pu, W. Gao, and Y. Que, "Experimental investigation on thermal performance of thermosyphon flat-plate solar water heater with a mantle heat exchanger," Energy, vol. 35, no. 9, pp. 3563-3568, 2010.

[27] R. B. Manoram, R. S. Moorthy, and R. Ragunathan, "Investigation on influence of dimpled surfaces on heat transfer enhancement and friction factor in solar water heater," Journal of Thermal Analysis and Calorimetry, vol. 145, no. 2, pp. 541558, 2021.

[28] S. A. Sakhaei and M. S. Valipour, "Thermal performance analysis of a flat plate solar collector by utilizing helically corrugated risers: an experimental study," Solar Energy, vol. 207, pp. 235-246, 2020.

[29] F. A. S. Silva and L. O. Salviano, "Heat transfer enhancement in a flat-plate solar water heater through longitudinal vortex generator," Journal of Solar Energy Engineering, vol. 141, no. 4, 2019.

[30] O. Sadeghi, H. A. Mohammed, M. Bakhtiari-Nejad, and M. A. Wahid, "Heat transfer and nanofluid flow characteristics through a circular tube fitted with helical tape inserts," International Communications in Heat and Mass Transfer, vol. 71, pp. 234-244, 2016.
[31] K. Sudalaiyandi, K. Alagar, V. J. MP, and P. Madhu, "Performance and emission characteristics of diesel engine fueled with ternary blends of linseed and rubber seed oil biodiesel," Fuel, vol. 285, article 119255, 2020.

[32] A. Karthick, K. Kalidasa Murugavel, K. Sudalaiyandi, and A. Muthu Manokar, "Building integrated photovoltaic modules and the integration of phase change materials for equatorial applications," Building Services Engineering Research and Technology, vol. 41, no. 5, pp. 634-652, 2020.

[33] S. Zhu, G. Yu, Y. Ma et al., "A free-piston Stirling generator integrated with a parabolic trough collector for thermal-toelectric conversion of solar energy," Applied Energy, vol. 242, pp. 1248-1258, 2019.

[34] A. Karthick, K. Kalidasa Murugavel, and L. Kalaivani, "Performance analysis of semitransparent photovoltaic module for skylights," Energy, vol. 162, pp. 798-812, 2018.

[35] P. Ramanan and A. Karthick, "Performance analysis and energy metrics of grid-connected photovoltaic systems," Energy for Sustainable Development, vol. 52, pp. 104-115, 2019.

[36] P. Ramanan, K. Kalidasa Murugavel, A. Karthick, and K. Sudhakar, "Performance evaluation of building-integrated photovoltaic systems for residential buildings in southern India," Building Services Engineering Research and Technology, vol. 41, no. 4, pp. 492-506, 2020.

[37] K. Yao, T. Li, H. Tao, J. Wei, and K. Feng, "Performance evaluation of all-glass evacuated tube solar water heater with twist tape inserts using CFD," Energy Procedia, vol. 70, pp. 332-339, 2015.

[38] S. Jaisankar, T. K. Radhakrishnan, and K. N. Sheeba, "Experimental studies on heat transfer and friction factor characteristics of forced circulation solar water heater system fitted with helical twisted tapes," Solar Energy, vol. 83, no. 11, pp. 1943-1952, 2009.

[39] A. Sable, "Experimental and economic analysis of concrete absorber collector solar water heater with use of dimpled tube," Resource-Efficient Technologies, vol. 3, no. 4, pp. 483490, 2017.

[40] W. Yuan, G. Fang, X. Zhang, Y. Tang, Z. Wan, and S. Zhang, "Heat transfer and friction characteristics of turbulent flow through a circular tube with ball turbulators," Applied sciences, vol. 8, no. 5, p. 776, 2018.

[41] P. Sivakumar, W. Christraj, M. Sridharan, and N. Jayamalathi, "Performance improvement study of solar water heating system," ARPN Journal of Engineering and Applied Sciences, vol. 7, no. 1, pp. 45-49, 2012. 